\title{
Review of Reconstructing 'Education' Through Mindful Attention: Positioning the Mind at the Center of Curriculum and Pedagogy, Oren Ergas
}

\author{
David Lewin ${ }^{1}$
}

Published online: 27 February 2018

(c) The Author(s) 2018. This article is an open access publication

\begin{abstract}
This paper provides a review of Reconstructing 'Education' through Mindful Attention: Positioning the Mind at the Center of Curriculum and Pedagogy by Oren Ergas. The review examines the central argument of the book, namely that present educational theory and practice avoids substantial self-inquiry, paying lip service to reflective practice but stopping short of any real encounter with the complex dynamics of the self. In Ergas' bold inquiry, we are invited to attend and to see for ourselves by considering perspectives and practices rooted in contemplative traditions. The educational context becomes clear as attention to the self entails formation of the self. However, I argue that it is not clear why contemplative traditions (or mindful attention defined by the text) are best placed to engage in such formation. I suggest that a central problem with the book is the conflation here of education and socialisation, and that more systematic treatment of educational questions might obviate some of the troubling issues around the failures of what is called the inner curriculum.
\end{abstract}

Keywords Mindfulness $\cdot$ Attention $\cdot$ Socialization $\cdot$ Experience $\cdot$ Contemplation

The basic concern of this book is to show that learning about ourselves is a vital educational endeavor. It is made strikingly plain that present educational theory and practice ignores or avoids substantial self-inquiry, paying lip service to reflective practice but stopping woefully short of any real encounter with the complex dynamics of the self. In this bold inquiry, we are invited to attend, to see for ourselves, in an argument whose simplicity masks a sustained dwelling with, and in, the perspectives and practices that are fundamentally rooted in contemplative traditions. Although only occasional reference is made to traditions of contemplative practice—e.g. Buddhist, Daoist, Hindu—it is clear that the author draws from deep wells in developing his argument. As a student of education, philosophy

David Lewin

david.lewin@strath.ac.uk

1 University of Strathclyde, Glasgow, UK 
and religious experience myself, I am fascinated by the orientation taken in this book. How could higher education, for instance, only concern curricula that stand 'outside' of the student? Contemplative traditions have consistently drawn attention to the fundamental nature of an 'inner' inquiry, and this book attempts to reorient wider educational structures in similar directions. So then, who is the thinker of 'my' thoughts? What control do I have over my mind and body? How might I disrupt the thought patterns that habitually appear? As an academic, I have lived with these questions always at the fringes of my interests. Only occasionally do I find them systematically addressed as they are in this book.

\section{What Makes Us?}

The book begins with a consideration of what makes the mind? The question might be shortened: 'What makes us?' a refinement that disrupts an implicit dualism. For we are not only minds, we are embodied, something Ergas goes on to take very seriously. However the question is framed, Ergas places education at the center of the making or forming process. Education is taken to be the fundamental agent of formation, and it needs 'reconstructing' because it is making us in ways that are inadequate. What is inadequate about the ways education makes us? The book does not pose this question in order to engage in a critical analysis of educational policies and practices, though such critical thinking should follow. Ergas is attempting to get at something more elusive and foundational: the inner curriculum that makes us, and that, we also make ourselves. It is better to say that the book seeks to rebalance education between an outer and inner curriculum; in an age of measurement, it seems that education is assumed to concern only the 'outer'. Drawing on Elliot Eisner's curricular model, Ergas argues that while curriculum theorists develop explicit curricula, and critical pedagogues examine the problems of implicit curricula, few theorists have considered inner curricula: what takes place within the personhood of the student, apart from the psychological developments that learning theories consider (pp. 105-110). The inner life of the student is of vital existential significance, but part of an excluded or ignored 'null curriculum.' Educational theory and practice largely fails to consider that which is decisive in the making of who we actually are: "[t]he narrative that runs in your mind throughout your day (e.g., your worries, hopes, dreams, thoughts of your social-image, body-image), your emotional life, and your bodily sensations are all subject matter that forms an inner curriculum" (p. 3).

In responding to the question of what it is that makes us, Ergas argues that the central problem of education is our tendency to take as necessary what is, in fact, contingent. Our identities, formed through habits and conditions that have shaped us, seem substantial and necessary, rather than ephemeral and contingent. Realising that we might be made differently is crucial to a balanced education, but is largely absent from the educational processes as Ergas presents them. Although we may learn about ourselves by way of encounters with others, we are seldom encouraged to learn about ourselves directly. My habitual responses, whether emotional or intellectual, seem so evidently mine that I do not generally inquire into, or experience, their contingency. As an ex-teacher at a Krishnamurti school, where inquiry into this inner space is made explicit, I find these inquiries very familiar and worthwhile. I agree with Ergas that educational patterns and processes contribute to the feeling of a stable and fixed identity and I appreciate the cultivation of detachment in this regard. Those patterns and processes fail to draw sufficient attention to the features 
and structures of our identity: that we are of a particular time, place, gender, ethnicity and so on, but, more importantly, that these particularities might be otherwise. While philosophers of identity have long addressed these issues, few take the direct route suggested by this book. Ergas does not go into great detail to explain the mechanisms, broadly arguing that the habituations and conditions of social life (mediated by language, cultural practices, ethical norms, media and so on) collude to enframe us. This does not just concern the formal identity markers of gender, ethnicity and so forth, but also our habits of mind: our hopes and dreams, desires and tastes, reactions and responses in daily life. Rather like our social media feeds that reflect the attitudes and dispositions of the user profile but are too easily experienced as proxies for wider, more 'objective' social attitudes, our inner life is at risk of becoming an 'echo chamber' in conversation only with itself, while deluding itself that its perspective is universal. Ergas laments how perception and reaction are not, in themselves, taken to be objects of educational inquiry, but are ignored or avoided as distractions to the educational process. He makes the point that, in fact, perception entails a reduction (or pruning) of the overwhelming mass of data that the senses might receive, to a coherent sensory input. As I will go on to argue, it is not clear why this process of perceptual reduction is considered educational, though Ergas is surely right that the selections and reductions of perception are formative: they have a significant role in making us who we are. I would question the idea that everything formative is best understood as educational, and I hope to convince you, dear reader, that this is more than a semantic issue.

The approach that Ergas initially takes, is to temporarily forget 'education' and 'society', and to study the mind; to ask "what experiences are available to the mind?" (p. 13). This is not treated simply as a theoretical inquiry, but also entails the "first-person experience" (p. 9) of the reader. This experience is enacted through mindful attention and contemplative inquiry whose goal for the reader is to provide a richer understanding of the analysis at hand. This direct method of experiential inquiry is uncommon among academic texts. Periodically the reader is asked to engage in short exercises in attention (spending, say, 3 min observing and writing down what comes to mind) so that the text weaves together the experiential and the conceptual. Some readers will be shifting uneasily in their metaphorical and literal armchairs, uncomfortable with the idea of a putatively academic text inviting mindful practice, suspicious, perhaps, that any clarity of argument would be compromised by experiential flights, or that these efforts presuppose an untenable separation of the intellect from experience. These experiments are, though, well-aligned with the deeper goals of the book: to argue that the mind can be reclaimed from 'society' and 'education' (p. 14) through mindful attention. So, the experiential approach is not only appropriate, well-judged and illuminating, it is arguably the only way to expose the problem being addressed: that educational discourse and practice fails to give any consideration to the inner life of human formation.

\section{The Education of Me}

Ergas presents a two-stage process of subjective formation: firstly, there is the experiencing I which has discrete, immediate sensory-laden experiences of things; secondly, through socializing forms of education, the I attaches particular meanings to significant experiences and objects, that help to constitute a sense of identity and form a narrative self. The favored analogy within the book is that of a necklace: 
Let us consider life as a concatenation of discrete moments of experience. Such moments are unimaginably rich in content (e.g., background noise, a thought, a word uttered, a fleeting sensation). Let us think of every content-possibility as a bead, hence every discrete moment of experience offers numerous such beads. Just as a child stands against the splendor of a box filled with beads so does our mind stand against the richness of experience and selects from its content moment-by-moment. The necklace formed in this process is your life as it unfolds through the act of threading (p. 46).

The formation of the narrative self, that emerges as a development from the experiencing I entails a reduction from a range of possible experiences and identities, to a singular person, the me self that is constructed by the interactions between the experiencing I and the social world. Borrowing from recent neuroscience, Ergas presents this as a process of pruning; contrary to the idea that the I expands to encompass a self in a larger social world, here the universal experience and infinite potential of the I must be pruned back so that a particular self can be 'made', a self with a particular, linguistic, social, cultural identity. This process of mind-making "prunes the mind based on the moment-to-moment process of perception and stamps those moments in the image of its particularity" (p. 61). The characteristic dualisms that result from this process are manifold: internal/external; in here/ out there; me/not me; subject/object. These dualisms arise through an implicit and ignored inner curriculum. Language has a key part to play in this individuation: "we are trained from day one to label the world based on language as our basic means for communication. Without anyone mentioning this to us we learn that labeling the world is desirable and effective." (p. 73). This leads Ergas to suggest a rather unconvincing progression from an originary pre-linguistic first nature, with language and labeling giving rise to a subsequent second nature. While Ergas is careful not to give easy ontological priority to this first nature, one can't help feeling that the pruning and labeling associated with the formation of the self are interpreted as something of a fall from the garden of pure attention. This structure is suggested by claims that, for instance, "we are trained" (p. 73) to label the world. We may be conditioned or socialized by the language we learn, but is that really training or education, and is it not better to acknowledge that language precedes our coming into the world? Most significantly, this points to a lack of distinction between certain key ideas in the book: namely socialization and education (or conditioning and training)? To be fair, Ergas does not use the term socialization that much, though it is not clear why. In other words, why does Ergas consider the issue of formation to be an educational one, rather than one of socialization or conditioning?

\section{Reconstructing Socialization Through Mindful Attention?}

The conflation of socialization and education is not uncommon among critical discourses in education: consider, for instance, the desire to expose the operation of a hidden curriculum, or the operations of social reproduction in educational spaces. Within the general terms of this book, the implications of this conflation are profound. For the argument turns upon the blindness that socialization-education enacts. Ergas calls this blindness to self the illusion of omniscience: "despite the fact that what we attend to is only one possible perspective on this moment, our most immediate sense is that it is the only available perspective" (p. 78). My own question here is whether the illusion of omniscience arrives through 
the absence of an inner curriculum and whether this illusion requires a reconstruction of education or socialization? For much of what Ergas says about education might be more commonly and, perhaps, more accurately and usefully described as socialization. Ergas discusses at length the issue that it is society that frames the pruning process. It is presented as a largely unconscious (or pre-conscious?) process or at least a process that we do not attend to. Isn't it this hidden-structural dimension that determines the process as one of socialization rather than education? Education can be distinguished from socialization by virtue of the fact that education entails an intentional and deliberate intervention between a student and the world. This intervention might be performed by a teacher but also can be done by the self to the self (as in the German idea of Selbstbildung). In general terms, this is what enables us to distinguish educational interventions from unconscious socialization or experiences in general. Within this still broad conception of education, one could identify a range of educational experiences whose concern is more specifically to draw attention to the contingencies of existence: to develop some kind of question about the nature of one's immediate perspective. From Ergas' point of view, the process of pruning the self is not presented as something intentional, that there is a policy for or established practices to support. This might be considered 'informal' education, but even this term suggests something deliberately 'cultivated' (Jeffs and Smith 2011). Rather, self-making seems to precede any decision to influence or shape it made by those that constitute it. There is something paradoxical about the idea of the self-forming itself. Little wonder then, that forming the self takes its cue from the outer social world. So what happens to the arguments in the book if we swap 'education' with 'socialisation'. For a start, the title would change to Reconstructing 'Socialisation' through Mindful Attention. This would be a worthwhile approach as long as one does not hastily cast socialization as a pathology. Socialisation surely needs our attention. But it is also evident, to borrow a phrase made popular (again) by Jacques Derrida and Bernard Stiegler, pharmacological in nature: socialisation is simultaneously what makes us who we are, but also what inhibits and prevents us from being who we are (or becoming more than that); it is both the poison and the cure. Socialisation is not something we could or would wish to do without, but it's very formative nature is what makes it what it is. That nature might carry some pathology or prejudice, but the formative processes themselves are not unfortunate excesses of socialization that we should attempt to legislate out. One cannot have one's socialized cake without eating it. One cannot have an identity as this without being, in a certain sense, not that.

But Ergas' point may be precisely that the intentional focus on self-formation should be much more developed and explicit than it is: that education should interrupt the problems and illusions of socialization. It is certainly plausible to argue that self-formation should not be left to the contingencies of socialization as an unconscious process, or the habituated mechanisms of human perception, action, and reaction. Self-formation should be precisely more educational by becoming an area of conscious pedagogical reflection: where the self reflects upon its relation to itself in a considered manner. This is certainly implied within much of the book and frees much of the argument from the danger that the inner curriculum is not 'education': "this is about making me into a more explicit curriculum" (p. 222).

But the question then becomes whether explicit examination of the structures and formations of identity could or should take place as a distinct inner curriculum: distinct, that is, from the outer curriculum. Or indeed, whether this distinction between inner and outer really stands up to any scrutiny. One could reasonably suppose that addressing the structure and formation of the I is, and generally always has been, an essential feature of the outer curriculum, even when appearing to address matters of the world, a point I will develop 
in due course. If there is no commitment to this kind of inner inquiry within general outer curricula around the world, the reasons might well pertain to a political or cultural ideology that reduces education to only that which is functionary, instrumental and measurable. So I am left to wonder whether the real target of the argument is the absence of the inner curriculum as such or a more general problem with curricula being appropriated to instrumentalism which has little time for that which cannot be measured. Where depression and despair make people less effective, we do see programmes that support self-inquiry, suggesting that the problem is broader than the absence of an inner curriculum. It might be replied that such interventions really amount to an 'inside-out' curriculum, in which the inner life is framed by concepts that rely on an outer theoretical construction. Nevertheless, I would still caution that the emphasis on a distinct inner curriculum might serve only to distract from the systemic educational issues that critical theorists have long sought to expose.

But the further point here is that the conception of education as an intentional intervention almost always entails some form of disruption of what we might regard as the conventions of subjectivity, and socialization (see e.g. Biesta 2010). To illustrate the point, Socratic pedagogy entails experiences of self-alienation or transformation, inducing the experience of aporia as a key moment (though not conclusion) of dialectic. Here the distinction between inner and outer curricula does not seem to hold since the knowledge derived through dialectic is always transformative of the self: Socratic education is little else than learning how virtue and knowledge are indivisible, thus fusing the inner nature and the nature of the world. An alternative illustration might be found in the German pedagogical tradition, which has also long explored education as being fundamentally a form of (self)-alienation. It is an alienation from the feeling of necessity that characterizes the Humboldtian experience of bildung, such as, for example, Goethe's travels through Italy which were self-consciously formative. Here bildung is precisely directed to the illusion of omniscience as discussed by Ergas. Moreover, there may be important educational reasons why the inner curriculum is not approached 'directly', but is stumbled upon by way of serious engagement with 'outer' cultural forms. For instance, we experience catharsis when fictional scenarios resonate with our own self-identity, a resonance that contributes to the formation of our own inner life when we experience it played out before us. Thus, Hamlet's dilemmas embody human questions that are our own: all the world's a stage. The task of education is surely to develop an outer curriculum that itself constitutes an inner curriculum. I am reminded of Ian Munday's reference (Munday 2012) to a scene from Alan Bennett's play The History Boys which illustrates this well:

Hector: And now for some poetry of a more traditional sort.

Timms: Oh, God!

Hector: Er, Timms, w-w-what is this?

Timms: Sir, I don't always understand poetry.

Hector: You don't always understand it? Timms, I never understand it. But learn it now, know it now, and you will understand it, whenever.

Timms: I don't see how we can understand it. Most of the stuff poetry's about hasn't happened to us yet.

Hector: But it will Timms, it will. And when it does, you'll have the antidote ready. Grief, happiness, even when you're dying. We're making your deathbeds here, boys. (Bennett 2004) 
So although Ergas argues that "[a]ttention can be "educated"” (p. 277) he seems only concerned with how mindful attention as a contemplative inner inquiry can educate attention, or at least does not go far enough in acknowledging that the education of attention might entail an encounter with things outside the self: music, poetry, maths and so on. Identity and agency are surely thereby educated, too, and we are disabused of the illusion of omniscience. There is more than a hint of withdrawal in Ergas' account of selfformation. Furthermore, consideration of the possibility that direct self-examination might be counter-productive would also be welcome within the discussion. Vicarious or indirect experience is not incidental to subjective formation, but may be the most effective process for it.

There are signs that a wider concern for the inner lives of students is entering educational discourse through, for instance, the widespread interest in character education, and the emerging centrality of social and emotional skills in recent OECD literature (OECD 2015). In England, this is framed in terms of 'spiritual, moral, social and cultural development' (SMSC) of pupils in schools, which has rather unfortunately been associated with a confused notion of the promotion of British values, itself a part of general securitization of education (see Lewin 2017). From the perspective of this book, I think these examples suggest that attempts to address the inner landscape are often usurped by the given contemporary ideology. So Ergas certainly has a point: the extent to which the outer and inner have bifurcated in the context of an assessment driven, quantitative, standards-based, neoliberal educational system, must be acknowledged. Attention to what will take us through the exam is surely the priority, to the detriment of education itself. While I am sympathetic to the analysis presented in this original and engaging book, I am not sure the answer is to directly employ an inner curriculum. Rather shouldn't the curriculum be uncoupled from neo-liberal ideology such that the questions of human existence are dwelt upon and experienced as real? That reality is neither simply inner or outer, but would unite the two.

Open Access This article is distributed under the terms of the Creative Commons Attribution 4.0 International License (http://creativecommons.org/licenses/by/4.0/), which permits unrestricted use, distribution, and reproduction in any medium, provided you give appropriate credit to the original author(s) and the source, provide a link to the Creative Commons license, and indicate if changes were made.

\section{References}

Bennett, A. 2004. The history boys. London: Faber and Faber.

Biesta, G. 2010. What is education for? Good education in an age of measurement: ethics, politics, democracy. Boulder: Paradigm.

Jeffs, T., and M.K. Smith. 2011. 'What is informal education?', The encyclopaedia of informal education. [http://infed.org/mobi/what-is-informal-education. Retrieved: 26th June 2017.

Lewin, D. 2017. Who's afraid of secularisation? Reframing the debate between Gearon and Jackson. British Journal of Educational Studies. Early View. https://doi.org/10.1080/00071005.2017.1305182.

Munday, I. 2012. Roots and Rhizomes-some reflections on contemporary pedagogy. Journal of Philosophy of Education 46: 42-59. https://doi.org/10.1111/j.1467-9752.2011.00825.x.

OECD 2015 Skills for social progress: The power of social and emotional skills www.oecd.org/edu/skill s-for-social-progress-9789264226159-en.htm. Retrieved: 26th June 2017. 